\title{
I AM SECURE ANDROID APPLICATION
}

\author{
Amrutha Barge $^{1}$, Nikita Vitthal Belokar ${ }^{2}$, Sonali Khodave ${ }^{3}$, Pallavi Gosavi ${ }^{4}$ \\ ${ }^{I}$ Department of Computer Science, Pimpri Chinchwad College of Engineering \\ ${ }^{2}$ Department of Computer Science, Pimpri Chinchwad College of Engineering \\ ${ }^{3}$ Department of Computer Science, Pimpri Chinchwad College of Engineering \\ ${ }^{4}$ Department of Computer Science, Pimpri Chinchwad College of Engineering
}

\begin{abstract}
The mobile device has been positioned to become the world's leading solution for every problem. The problem can be any emergency case like natural disaster, kidnapping etc. in which smart phones can be used to provide help. This article outlines use of mobile technology through which we can ensure person's safety. This application provides you and your family with a one-click automated emergency communication system that contacts up to 3 family or friends. It will even send your location Because of it becomes easy for you to locate and contact the closest Police Department, Ambulance Service, and Hospital. This mobile application can be useful to optimize the workflow in emergency cases.
\end{abstract}

\section{INTRODUCTION}

The enormous trend of crimes is happening now days so there is a need of such application which runs on smart phones. By using this "I am secure app" the victims can report any emergency cases as fast as it could enable to act effectively. In this the client that is the user of android phone and the cops will create the account for access of this application. After creating this account the client will get the username and password. In emergency the client with android phone will send the emergency message to server including current position of the victim. The server will in turn send this emergency message to cops. Then this cops will take the respective action to the emergency an $\mathrm{d}$ will give notification. We are also using the GSM module it will be beneficial whenever the client is not having internet connection .The GSM module will be having one helpline number, and this module will be connected to server .In emergency the client will send message to this GSM module and via server it will send to cops.

\section{PROBLEM STATEMENT}

Development of this project is to ensure human safety in emergency cases. We are developing mobile application that provide client with one click automated emergency system that contacts up to 3 registered numbers. It will even send clients' location. In case of any emergency, client will use this application which is already installed in clients' mobile. With one click; client will initiate the service by which the message will be send to the server. In case internet is not available on clients mobile the client himself will send the message to the helpline number provided. This helpline number is of a GSM device which will always be connected to the server. The server will in turn read the message received by the device. Now the server will send the information to the nearest police station according to the report generated. Then the cops will take the further action and provide notification on the account provided by the server.

\section{PURPOSE OF STUDY}

i. In this modern era, human safety has been greatly threatened due to various crimes, attacks and other misfortunes taking place.

ii. Almost $90 \%$ of the people around the globe are aware of the technology and use it in their daily life.

iii. Mobile phone is the only device which is carried and useful during time of emergency.

iv. Keeping this point in mind, the idea of developing this application has been emerged to provide human safety.

v. Informing about the emergency is as important as reporting and taking action within certain amount of time.

vi. Knowledge about the victim's location in the report can save time which can be used in taking further action.

vii. Using this technology we can prevent the severity of any problem that can be caused by disaster or any misfortune.

viii. Hence, this application can be proved to be useful in reporting emergency along with the location. 


\section{METHODOLOGY}

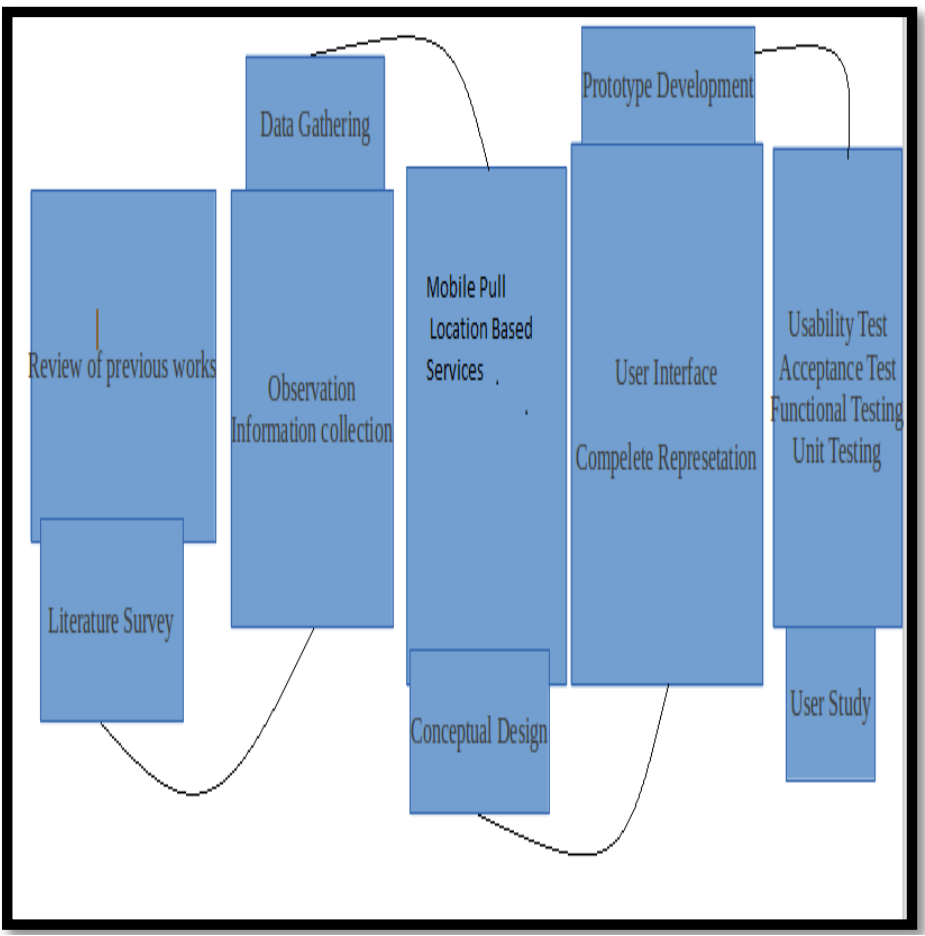

Fig.1 Research Methodology Diagram (a)

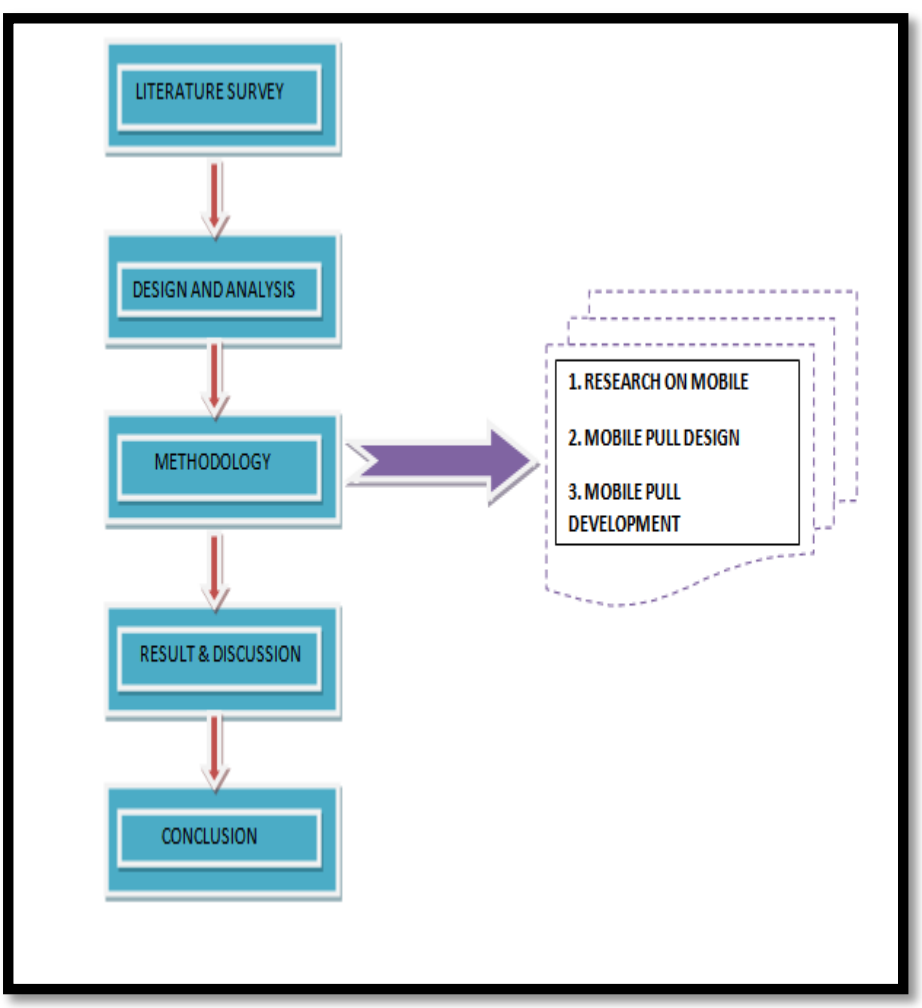

Fig.2 Research Methodology Diagram for dev developing the android application (b)
We begin with the literature survey and the previous work done in other research papers. This is the extension to the SOS emergency messages. Then we started with data gathering by analyzing previously implemented SOS emergency messages. In designing phase the suitable architecture diagram and modules were identified. We will be using mobile pull service.

First we need to review the previous works by doing literature survey. Data is to be gathered by observing and collecting information. Determine which service is to be used to build the project. Plan for the design of the project staring with the user interface Check the running of the project by testing it.

\section{HOW IT WORKS}

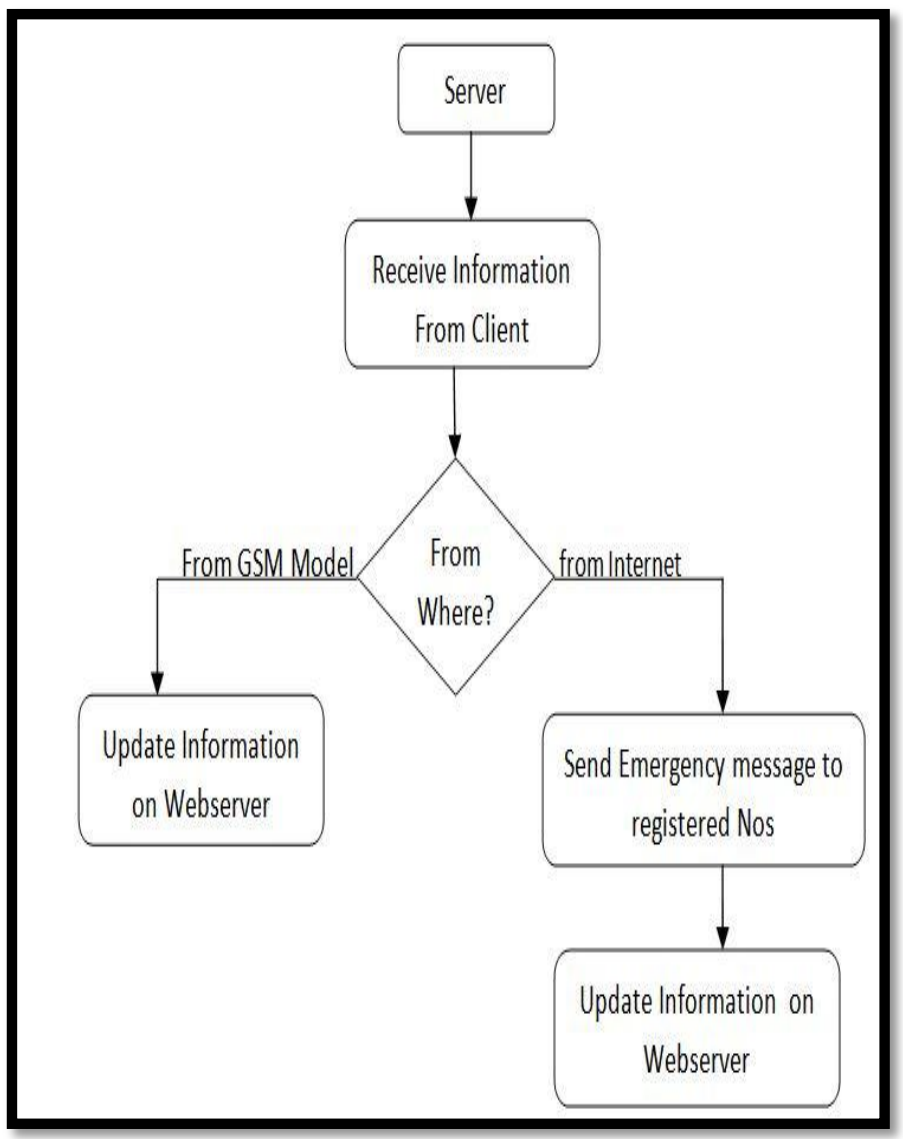

Fig.3 work flow on server side

The working of the android application on the client as well as the server side is as follows:

1. If user is android client then

(a) First install the developed application.

(b) Follow the given registration steps:

i. Fill the personal information.

ii. Provide three contact numbers to which the message will be sent in emergency. 
2. Else If user is police/hospital

(a) Create an account on the web server which includes registered user id and password.

3. When in emergency android client can use this application using the following steps

(a) If emergency is of higher priority then

i. long press the icon which will directly send only the emergency report to the server.

(b) Else

i. Select the type of emergency from menu.

ii. Select your current location from menu

(c) Send this information to the server.

4. For non-android clients the above information can be sent through message to available helpline number.

5. Server will receive above information from clients and decrypt the location from the received information.

(a) If received information is from internet then

i. send the emergency messages to three registered numbers by client and

ii. Update this information on the webserver for the respected users according the priority (police station/hospital).

(b) If received information is from the GSM model then

i. update this information on the webserver for the respected users(police station/hospital).

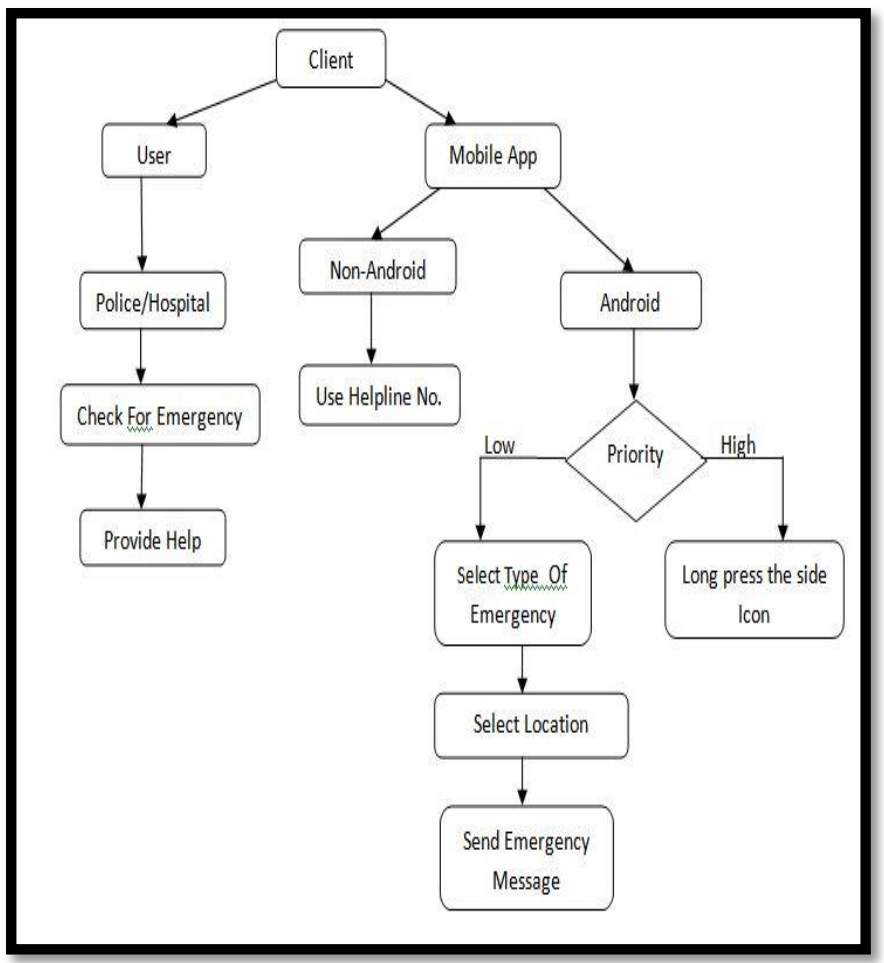

Fig.4 work flow on client-side

\section{PROPOSED ARCHITECTURE}

The above architecture shows the flow of the design for the current application being developed.It involves three main components: firstly two types of user i.e android client and desktop client.Secondly the GSM and the server.

a. Android Client :- Here the android client will be using the application which can ensure human safety. This application helps in selecting location and is capable of sending a message to the server.

b. Non-Android Client :- In case of other clients and in unavalaibility of internet facility,user can send the text message to the paritcular helpline number containing location and the need of emergency service in the specific format.

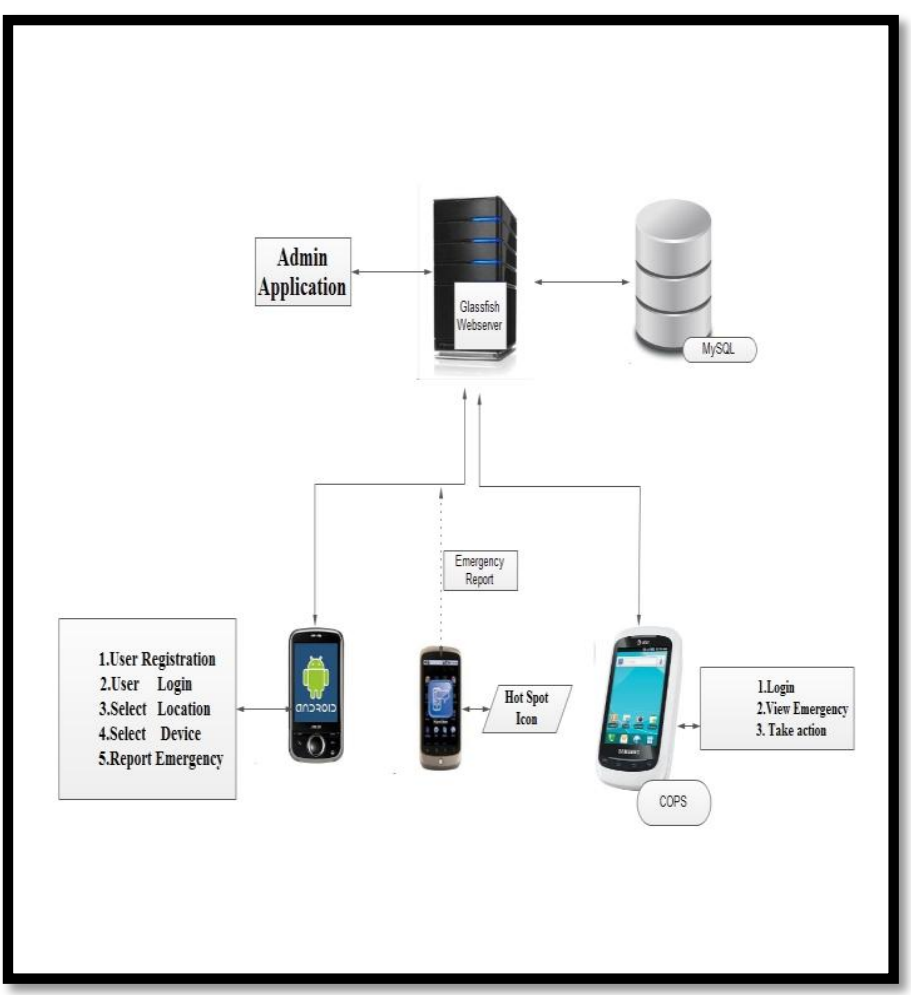

Fig.5 overview of the android application

c. Desktop Client :-It will be developed for the emergency service providers like police,hospital,fire brigade and other helping agencies. They need to create account on the server and can receive the emergency alerts as notifications. They can access notifications from their accounts. After taking actions or solving the issues it can be updated in the accounts as the issue has been solved.The emergency cases can be viewed according to the location of the departments.

d. GSM Device:- This acts as a intermediate module between non android clients and server.It communicates on behalf of the client with the 
server.Help line number will be provided to this device.This GSM device is in turn connected to the server.

e. Server:-There are two types of inputs recieved by the server one is directly through android client and second through non-android client via GSM.After receiving input the server will check for the registerd numbers in the database and send emergency message with the location of the victim embeded in it. The respective location police department account will be updated with this report.The server will extract the information about the location from the GSM device and the further process will be followed as above.

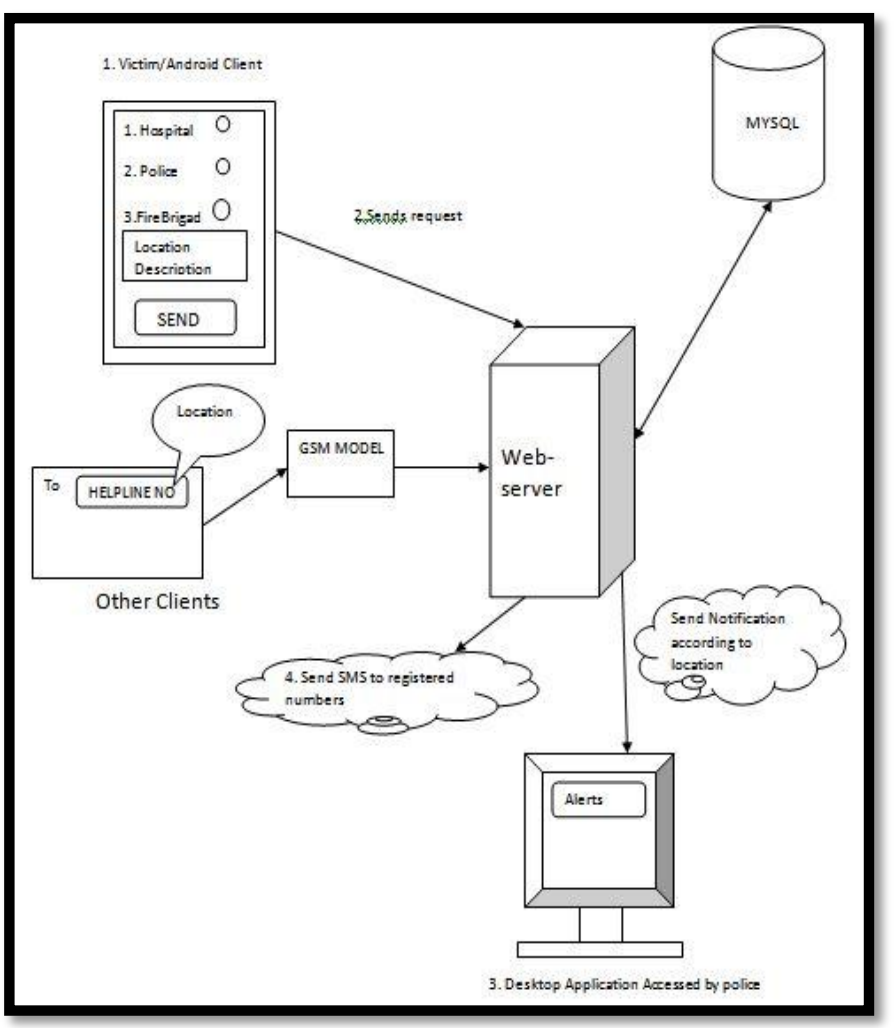

Fig.6 Detailed Architecture

The below n-tier architecture shows the important part that is internet may acess HTTP server.

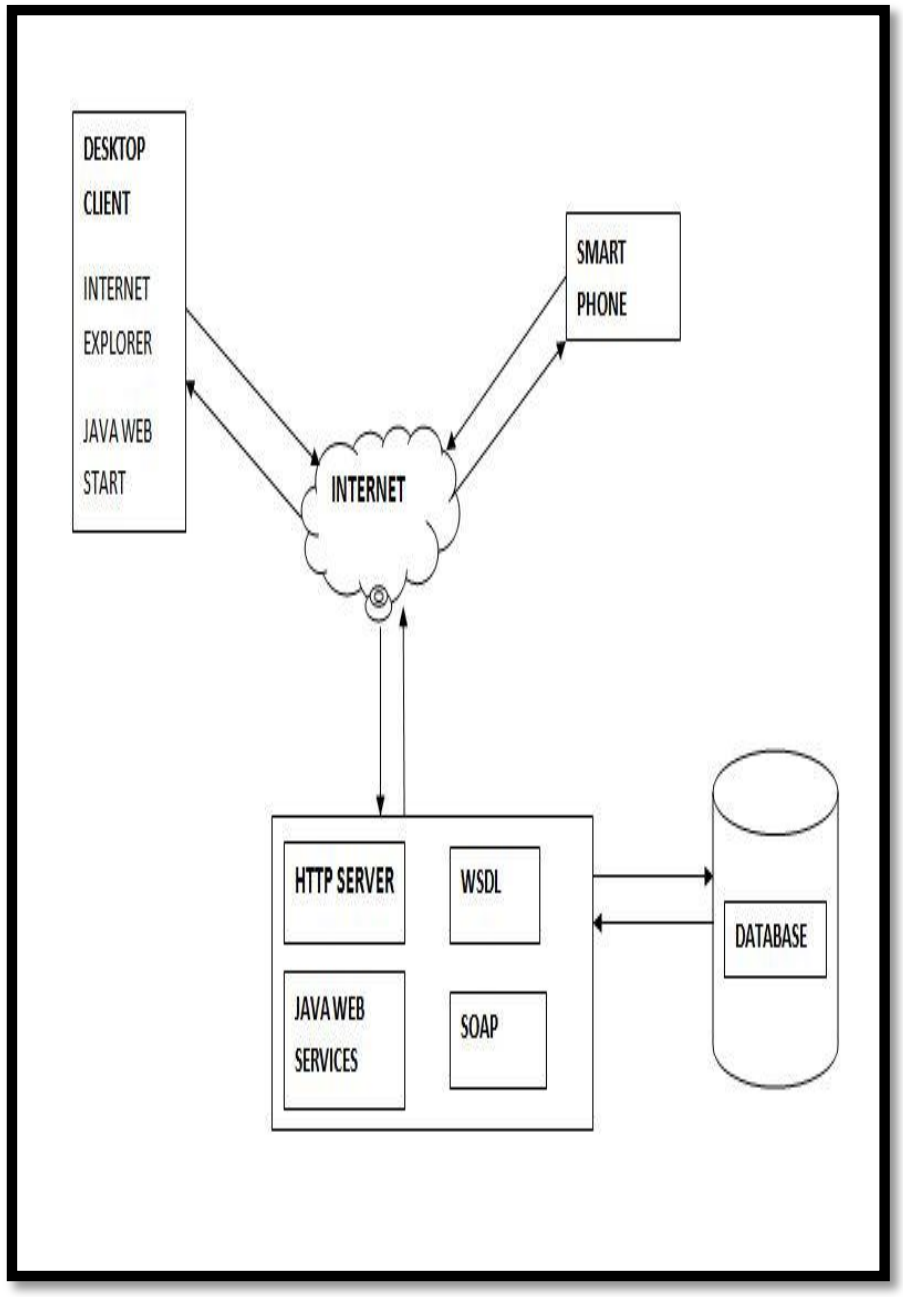

Fig.7 n-tier architecture for the web services

\section{CONCLUSIONS}

The web services are considered to be playing the vital role in rendering the information for building mobile application prototype. The information will always be updated based on information the user feeds in to the system. With the help of this application the policeman can easily use this device to detect any kind of emergency. The emerging cloud device is proved to be useful for fighting crimes when there is increase in crimes.

\section{ACKNOWLEDGMENTS}

This Research was supported by Computer Science department of Pimpri Chinchwad College of Engineering Pune. We would like to thank the reviewers, faculty members and other supporters for their suggestions and contribution. Also thankful for the continuous support of lecturers to research on this subject 


\section{REFERENCES}

[1] Dr Rosidah Ibrahim(2010).”Communication System In Emergency Medical And Trauma Services Ministry of Health."

[2] Jonathan D.Mayer(1980),"Response Time and Its Significance in Medical Emergencies", Geographical Review, American Geographical Society

[3] Jovilyn Therese B. Fajardo, Carlos M. Oppus, “A mobile disaster management system using the android technology," WSEAS Transactions on Communications.

[4] T D' Roza and G Bilchev (2004)." An Overview of Location Based Services, Location and Personalisation: Delivering Online and Mobility Services."British Telecommunication Plc.p20-27

[5] A.R. Awad, I. Von Poser, and M.T. Aboul-Ela, Advanced Intelligent Technique of Real Genetic Algorithm for Traveling Salesman Problem Optimization, Proceedings of the 9th WSEAS International Conference on Data Networks, Communications, and Computers, Trinidad and Tobago, November 5-7, 2007, pp. 447-453.

[6] GIS for Fire Station Locations and Response Protocol, An ESRI ${ }^{\circledR}$ White Paper 